\title{
Synergistic hepatotoxicity by cadmium and chlorpyrifos: Disordered hepatic lipid homeostasis
}

\author{
WEI HE ${ }^{1,2}$, WENLI GUO ${ }^{2}$, YI QIAN ${ }^{2}$, SHUPING ZHANG ${ }^{2}$, DIFENG REN ${ }^{1}$ and SIJIN LIU $^{2}$ \\ ${ }^{1}$ Beijing Key Laboratory of Forestry Food Processing and Safety, College of Biological Sciences and Biotechnology, \\ Beijing Forestry University, Beijing 100083; ${ }^{2}$ State Key Laboratory of Environmental Chemistry and Ecotoxicology, \\ Research Center for Eco-Environmental Sciences, Chinese Academy of Sciences, Beijing 100085, P.R. China
}

Received May 13, 2014; Accepted January 23, 2015

DOI: $10.3892 / \mathrm{mmr} .2015 .3381$

\begin{abstract}
Due to its extensive application, chlorpyrifos (CPF) has contaminated a diverse range of environmental substrates, fruits and vegetables. A number of studies have suggested that CPF may incur adverse effects on human health, including neurotoxicity, hepatotoxicity and endocrine disruption. Additionally, cadmium (Cd) is one of the most prevalent environmental heavy metals, as a result of considerable use in a wide spectrum of industrial fields. Exposure to $\mathrm{Cd}$ can cause several lesions in various organs, including the liver, kidneys and lungs. CPF and Cd often co-exist in the environment, food and crops, however, their joint exposure and potential synergistic toxicity are largely neglected and unrecognized. Our previous study characterized an interaction between $\mathrm{CPF}$ and $\mathrm{Cd}$, which may occur via bonding between $\mathrm{Cd}^{2+}$ and the nitrogen atom in the pyridine ring of $\mathrm{CPF}$, or the chelation between one $\mathrm{Cd}^{2+}$ and two CPF molecules. Our previous study also identified increased hepatotoxicity induced by CPF and $\mathrm{Cd}$ together compared with the individual compounds. In the present study, the effects of the concomitant exposure of CPF and $\mathrm{Cd}$ on lipid metabolism in hepatocytes was investigated.
\end{abstract}

Correspondence to: Professor Difeng Ren, Beijing Key Laboratory of Forestry Food Processing and Safety, College of Biological Sciences and Biotechnology, Beijing Forestry University, 35 Qinghua East Road, Haidian, Beijing 100083, P.R. China

E-mail: rendifeng@bjfu.edu.cn

Professor Sijin Liu, State Key Laboratory of Environmental Chemistry and Ecotoxicology, Research Center for Eco-Environmental Sciences, Chinese Academy of Sciences, 18 Shuangqing Road, Haidian, Beijing 100085, P.R. China

E-mail: sjliu@rcees.ac.cn

Abbreviations: CPF, chlorpyrifos; Cd, cadmium; OPPs, organophosphorus pesticides; FASN, fatty acid synthase; SREBP, sterol regulatory element-binding protein; DMSO, dimethyl sulfoxide; FBS, fetal bovine serum; ACC, acetyl-coenzyme A carboxylase; CoA, coenzyme A

Key words: chlorpyrifos, cadmium, synergistic toxicity, lipid metabolism
The results demonstrated an accumulation of lipids in hepatocytes, induced by the CPF and Cd complex, which was fundamentally distinct from its parental chemicals. Notably, the molecular mechanism by which the CPF-Cd complex significantly induced hepatic lipogenesis was revealed, elevating the concentrations of sterol regulatory element-binding protein-1 and fatty acid synthase. These findings pave the way for future studies in recognizing synergistic biological effects between pollutants.

\section{Introduction}

Organophosphorus pesticides have been widely used in agricultural environments, since the ban of organochlorine insecticides, to protect crops against a range of pests due to their broad spectrum of insecticidal activity, effectiveness and their non-persistence in the environment (1). Despite the benefits of pesticides, residues may remain in crops, animal feed and environmental substrates, leading to contamination and potential human exposure through the food chain (2-4). Chlorpyrifos (CPF) is a major type of organophosphorus pesticide and is currently used in the production of $>40$ crops and fruits, including peaches, citrus fruits, almonds and grapes (1). $\mathrm{CPF}$ and its metabolites have been detected in farm animals, including cattle and sheep $(1,5)$, and CPF residues or metabolites have also been detected in food and human urine (6). In addition, CPF has been found in the umbilical cord blood from female individuals living in urban environments (7). CPF has been confirmed as a neurotoxin by inhibiting acetylcholinesterase in the central nervous system (8). This can damage the nervous system, resulting in dizziness, nausea, confusion and, at a high concentration, respiratory paralysis and mortality. Additionally, a previous study demonstrated that $\mathrm{CPF}$ incurs developmental toxicity in rats at concentrations of $25 \mathrm{mg} / \mathrm{kg} /$ day, which was a maternally toxic dose (9). Similar to the majority of environmental pollutants, $\mathrm{CPF}$ elicits significant cytotoxicity through generating oxidative stress (10-12).

Cadmium $(\mathrm{Cd})$ is one of the most prevalent environmental heavy metals, and human exposure to $\mathrm{Cd}$ is associated with a number of toxicities, including hepatotoxicity, DNA damage and cell apoptosis (13-15). Notably, CPF and Cd often coexist in the same environmental media and food chains, causing simultaneous exposure to organisms $(16,17)$ and resulting in 
common toxicities, including carcinogenicity and hepatotoxicity (18-20). Our previous study characterized an interaction between $\mathrm{Cd}$ and $\mathrm{CPF}$, and this interaction likely occurs due to bonding between $\mathrm{Cd}$ and nitrogen atoms in the pyridine ring of $\mathrm{CPF}$, or the chelation between one $\mathrm{Cd}^{2+}$ and two $\mathrm{CPF}$ molecules (21). The joint hepatotoxicity of $\mathrm{Cd}$ and $\mathrm{CPF}$ to HepG2 cells was also demonstrated, with the Cd-CPF complex increasing the level of apoptosis by compared with its parental components (21).

Hepatic lipid metabolism is important in governing the whole body energy metabolism, as the liver is the major site for the storage and release of glucose and lipids $(22,23)$. Lipid accumulation within liver has been suggested to cause obesity, insulin resistance and type II diabetes (22-24), and also predisposes individuals to nutritional stresses. Increasing evidence suggests that fatty acid synthase (FASN) is a critical regulator of hepatic lipid homeostasis, including fat and cholesterol synthesis $(25,26)$. FASN encodes one of the key enzymes involved in fatty acid synthesis and is required for the de novo synthesis of fatty acids (27). Upregulated expression levels of FASN have been reported in various types of human cancer, and has been suggested to contribute to poor prognosis and recurrence of these types of cancer (28). Sterol regulatory element-binding protein (SREBP) is the predominant transcriptional activator of FASN $(29,30)$, and previous studies have revealed that the increased expression of SREBP-1 is significantly associated with the extent of fatty liver in mouse models of diabetes mellitus (31-33). The present study aimed to investigate the synergistic effect of $\mathrm{Cd}$ and $\mathrm{CPF}$ on fat metabolism and fat accumulation in hepatocytes.

\section{Materials and methods}

Chemicals and reagents. CPF was purchased from Shuangma Fine Chemical Co., Ltd. (Nantong, China) and was dissolved in dimethyl sulfoxide (DMSO) (Solarbio Science \& Technology Co., Ltd., Beijing, China). The final concentration of DMSO was $<0.1 \%$ in the culture medium. $\mathrm{CdCl}_{2}$ was purchased from Sigma-Aldrich (St. Louis, MO, USA). Sterile water was used to dissolve the $\mathrm{CdCl}_{2}$, and the stock solution was filtered through a $0.45 \mathrm{~mm}$ membrane (Solarbio Science \& Technology Co., Ltd.).

Cell culture. The HepG2 human hepatic carcinoma cell line was purchased from Shanghai Cell Bank of Type Culture Collection of the Chinese Academy of Sciences (Shanghai, China). The HepG2 cells were cultured at a concentration of $5.0 \times 10^{3}$ cells/well in RPMI-1640 medium (Gibco Life Technologies, Carlsbad, CA, USA) supplemented with $10 \%$ fetal bovine serum (FBS; HyClone, Logan, UT. USA) and $100 \mathrm{U} / \mathrm{ml}$ penicillin-streptomycin (HyClone) at $37^{\circ} \mathrm{C}$ in an atmosphere of $5 \% \mathrm{CO}_{2}$. The cell culture medium was changed every day and the cells were passed every other day.

Cytotoxicity assessment. The cytotoxicity was initially screened using an MTT assay (Invitrogen Life Technologies, Carlsbad, CA, USA). Briefly, the cells were inoculated and cultured overnight at $37^{\circ} \mathrm{C}$ in 96 -well plates (Corning, Inc., New York, NY, USA) at a density of $8.0 \times 10^{3}$ cells/well in RPMI-1640 medium supplemented with penicillin, streptomycin $(100 \mathrm{mM})$ and $1 \%$ FBS. Following culture, the HepG2 cells were treated with various concentrations of $\mathrm{CPF}(10,50,100,500,1,000,1,500$, $2,000$ or $2,500 \mu \mathrm{M})$ or $\mathrm{Cd}(5,10,20,40,60,80$ or $100 \mu \mathrm{M})$ for a further $24 \mathrm{~h}$ at $37^{\circ} \mathrm{C}$, and $20 \mu 1 \mathrm{MTT}(5 \mathrm{mg} / \mathrm{ml})$ was then added to each well. Following an additional $4 \mathrm{~h}$ incubation at $37^{\circ} \mathrm{C}$, $100 \mu \mathrm{l}$ DMSO was added to each well, followed by absorption assessment at $490 \mathrm{~nm}$ on a microplate reader (Multiskan MK3; Thermo Fisher Scientific, Co., Ltd., Waltham, MA, USA). The synergistic toxicity was further determined using an Alamar Blue assay (Invitrogen Life Technologies) and a bromodeoxyuridine (BrdU) assay (Roche Diagnostics, Mannheim, Germany). Similar to the MTT assay, following treatment with $10 \mu \mathrm{M} \mathrm{CPF}$ or Cd, $10 \mu 1$ Alamar Blue reagent (Invitrogen Life Technologies) was added to each well and incubated for $2 \mathrm{~h}$ at $37^{\circ} \mathrm{C}$, prior to the plates being read on a microplate reader with an emission wavelength of $590 \mathrm{~nm}$ and an excitation wavelength of $540 \mathrm{~nm}$. The BrdU assay was performed according to the manufacturer's instructions, as described previously (34).

High glucose exposure. The cells were exposed to high glucose, as described previously (35). Briefly, the HepG2 cells were seeded into 6-well plates in RPMI-1640 medium supplemented with $10 \%$ FBS. The cells were grown to $70 \%$ confluence, prior to being maintained in serum-free RPMI-1640 medium, containing high concentrations of glucose $(30 \mathrm{mmol} / \mathrm{l})$ overnight. The cells were subsequently treated with $\mathrm{Cd}$ and $\mathrm{CPF}$, as described above.

Determination of total cholesterol and triglyceride levels. The intracellular concentrations of total cholesterol and triglycerides were assayed in the HepG2 cell lysates, according to the manufacturer's instructions of the Triglycerides Assay and Total Cholesterol Assay kits (Nanjing Jiancheng Bioengineering Institute, Nanjing, China). The cell pellet was collected and $0.3 \mathrm{ml}$ Triton-X $100(1-2 \%)$ was added. It was lysed for $30 \mathrm{~min}$ prior to the start of the assays according to the manufacturer's instructions. The mixture was incubated at $37^{\circ} \mathrm{C}$ for $5 \mathrm{~min}$, followed by reading with the microplate reader at $590 \mathrm{~nm}$.

Western blotting. Following the treatment with $\mathrm{Cd}$ and CPF, described above, the HepG2 cells were collected and washed twice with phosphate-buffered saline (Solarbio Science \& Technology Co., Ltd.). The harvested cells were lysed in radioimmunoprecipitation lysis buffer supplemented with protease inhibitor cocktail (Roche Diagnostics) on ice for $30 \mathrm{~min}$. The cells were subsequently centrifuged at $12,000 \mathrm{xg}$ for $10 \mathrm{~min}$. The supernatants were collected and were subjected to 10\% SDS-PAGE (gel, Beijing ComWin Biotech Co., Ltd., Beijing, China; SDS buffer, Solarbio Science \& Technology Co., Ltd.) and were transferred onto nitrocellulose membranes (Solarbio Science \& Technology Co., Ltd.). The membranes were incubated with primary antibodies against SREBP-1 (1:200; bs-1402R), FASN (1:200; bs-1498R-PE) and $\beta$-actin (1:1,000; bs-0061R) (Bioss, Beijing, China) in 5\% milk overnight at $4^{\circ} \mathrm{C}$. They were then washed 3 times in Tris-buffered saline with Tween-20 (Solarbio Science \& Technology Co., Ltd.) for $5 \mathrm{~min}$, and then incubated with anti-rabbit-horseradish peroxidase secondary antibodies (1:8,000; ComWin Biotech Co., Ltd.) for $1 \mathrm{~h}$ at $37^{\circ} \mathrm{C}$ in $5 \%$ milk, then washed again in a similar manner. The target proteins were colored by a chemical 
A

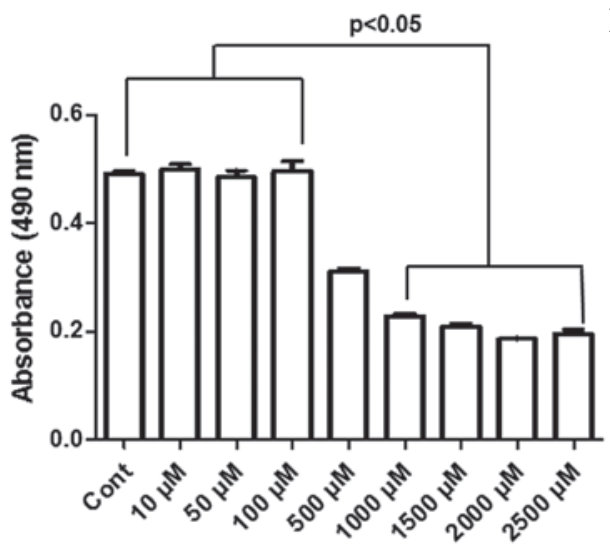

B

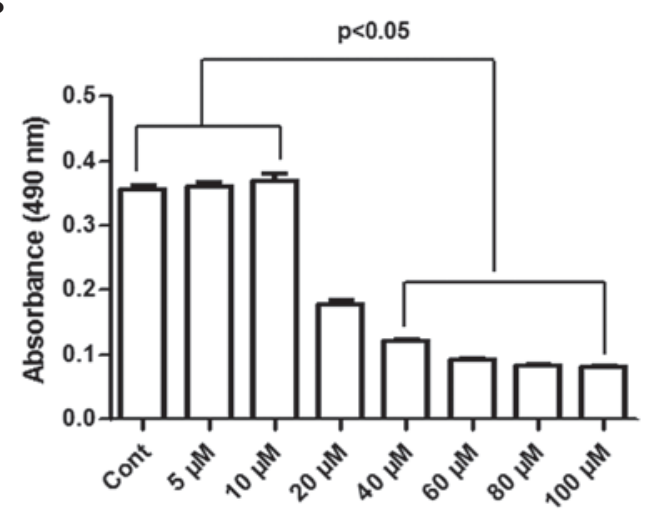

Figure 1. Cytotoxicity assay of HepG2 cells treated with various concentrations of CPF or Cd ${ }^{2+}$. The cytotoxicity was assessed by measuring absorbance following an an MTT assay of the HepG2 cells 24 h after treatment with 10-2,500 $\mu \mathrm{M}$ (A) CPF and (B) Cd ${ }^{2+}$ (n=5). CFP, chlorpyrifos; Cd, cadmium; Cont, untreated control.

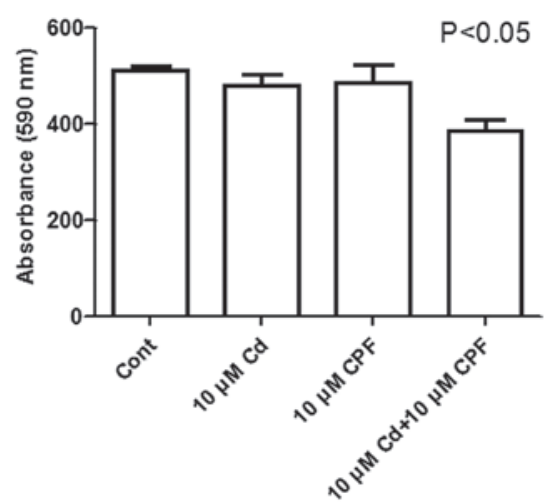

B

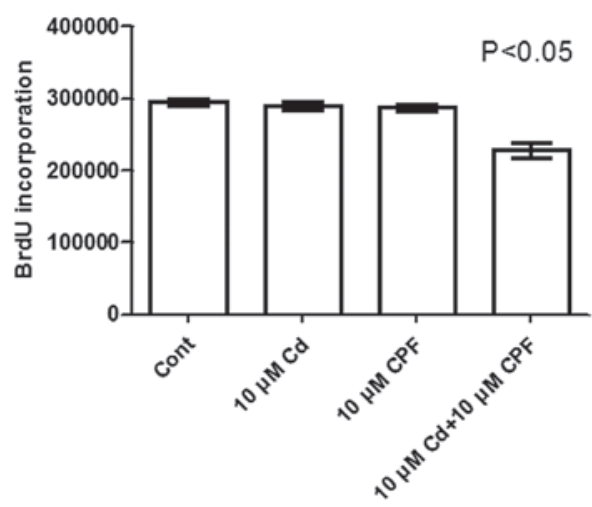

Figure 2. Cell viability following concomitant exposure of CPF and Cd ${ }^{2+}$ in HepG2 cells. (A) Alamar Blue and (B) BrdU assays were performed on HepG2 cells treated with $\mathrm{CPF}$ and $\mathrm{Cd}^{2+}$ either alone $(10 \mu \mathrm{M}$ each) or concomitantly for $24 \mathrm{~h}(\mathrm{n}=4-5)$. CPF, chlorpyrifos; Cd, cadmium; BrdU, bromodeoxyuridine; Cont, untreated control.

method. The intensity of the protein bands were assessed using Image J software, version 1.48 (NIH, Bethesda, MD, USA).

Statistical analysis. Using SPSS software, version 17.0 (SPSS, Inc., Chicago, IL, USA) Student's two-tailed t-test was performed to analyze the experimental data between two groups, and one-way analysis of variance was used to analyze the mean differences between groups relative to the control. The data are expressed as the mean \pm standard deviation. $\mathrm{P}<0.05$ was considered to indicate a statistically significant difference.

\section{Results and Discussion}

The toxicity of combinations of environmental pollutants is important when determining the health risks of each individually. $\mathrm{Cd}$ and $\mathrm{CPF}$ have been demonstrated to have common targets and elicit similar phenotypes, including hepatotoxicity $(11,36-38)$. Our previous study revealed a novel interaction between $\mathrm{Cd}$ ions and $\mathrm{CPF}$, and described the cytotoxicity induced by the Cd-CPF complex (21). The present study hypothesized that the synergistic cytotoxicity between $\mathrm{CPF}$ and $\mathrm{Cd}^{2+}$ was likely to cause metabolic disorders in hepatocytes.
Initially, a series of experiments were performed to confirm the synergistic toxicity, as previously discussed (21). As shown in Fig. 1A, the MTT assay revealed that CPF induced significant toxicity to the HepG2 cells following 24 h treatment with $0.5,1$, 1.5, 2 and $2.5 \mathrm{mM}$, in a dose-dependent manner, compared with the control $(\mathrm{P}<0.05)$. The half maximal inhibitory concentration $\left(\mathrm{IC}_{50}\right.$ ) was $\sim 0.5 \mathrm{mM}$ in the HepG2 cells (Fig. 1A). No cytotoxicity was observed in the HepG2 cells at CPF concentrations $\leq 100 \mu \mathrm{M}$ (P>0.05; Fig. 1A). In addition, the cytotoxicity of $\mathrm{Cd}$ was determined in HepG2 cells treated with 5, 10, 20, 40, 60, 80 and $100 \mu \mathrm{M} \mathrm{CdCl}_{2}$. Following treatment for $24 \mathrm{~h}$, no toxicity was observed $\leq 10 \mu \mathrm{M}$ (P>0.05; Fig. 1B), however, $\mathrm{CdCl}_{2}$ induced significant cell death at $\mathrm{Cd}$ concentrations $>10 \mu \mathrm{M}(\mathrm{P}<0.05)$. The $\mathrm{IC}_{50}$ value for $\mathrm{Cd}^{2+}$ was $\sim 20 \mu \mathrm{M}$ (Fig. 1B).

Previous studies have suggested that the formation of a complex between chemicals alters their transport across the cell membrane and increases intracellular localization, resulting in enforced cytotoxicity, which may not occur with individual chemicals (39-41). A classical interaction of CPF was identified with methyl mercury, as the formation of this complex significantly increased the bioaccumulation of methyl mercury, coupled with increased toxicity (42). Our previous study demonstrated 


\section{Cont}
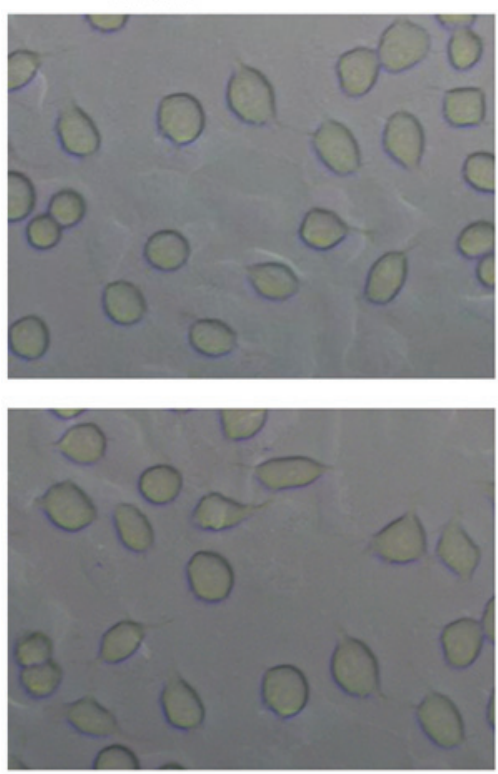

$10 \mu \mathrm{M} \mathrm{CPF}$

\section{$10 \mu \mathrm{M} \mathrm{Cd}$}
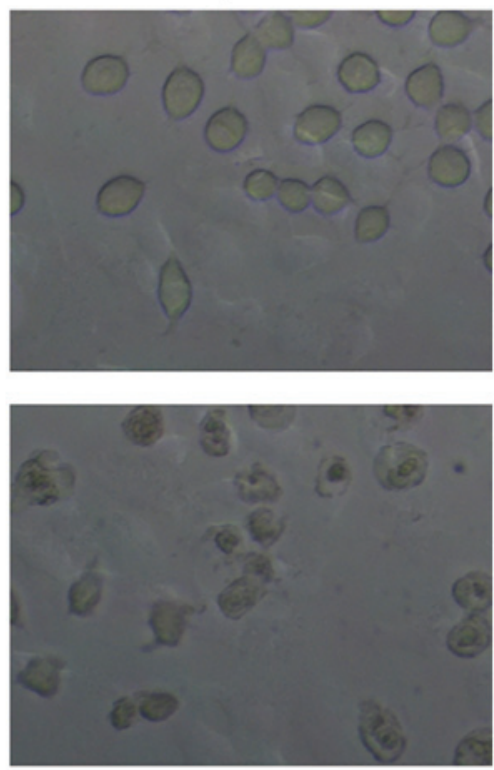

$10 \mu \mathrm{M} \mathrm{CPF}+10 \mu \mathrm{M} \mathrm{Cd}$

Figure 3. Morphological changes of the HepG2 cells following concomitant exposure of $\mathrm{CPF}$ and $\mathrm{Cd}^{2+}$. The phase-contrast images demonstrated morphological changes of the HepG2 cells following treatment with $\mathrm{CPF}$ and $\mathrm{Cd}^{2+}$ either alone or concomitantly (magnification, x200). CPF, chlorpyrifos; Cd, cadmium; Cont, untreated control.

A

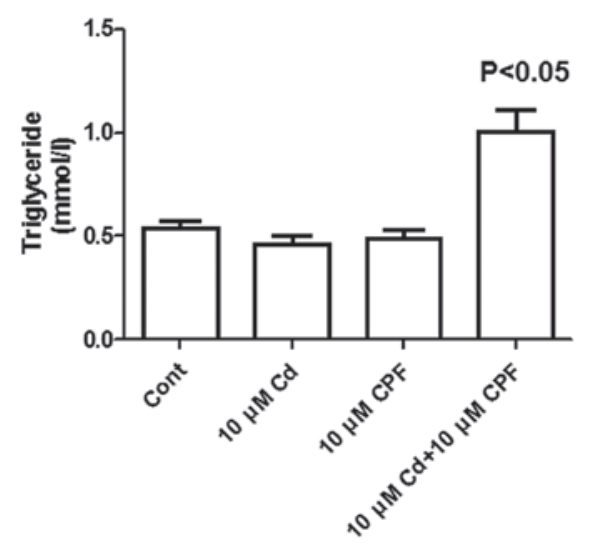

B

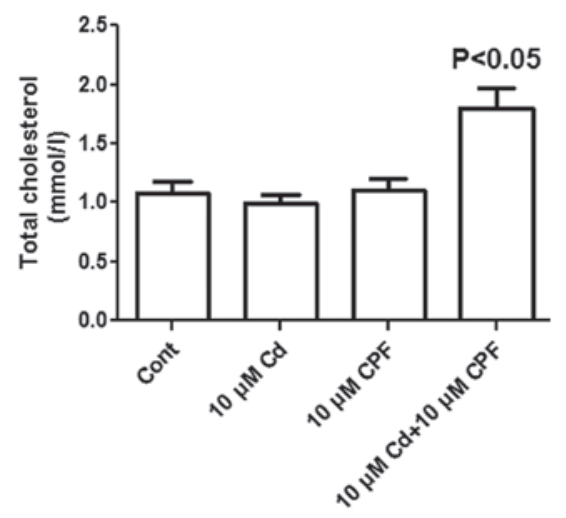

Figure 4. Lipid alterations due to the synergistic toxicity of $\mathrm{CPF}$ and $\mathrm{Cd}^{2+}$. The levels of intracellular (A) triglycerides and (B) total cholesterol in the HepG2 cells treated for $24 \mathrm{~h}$ with $\mathrm{CPF}$ and $\mathrm{Cd}^{2+}(10 \mu \mathrm{M}$ each) either alone or concomitantly ( $\mathrm{n}=4-5)$. CPF, chlorpyrifos; $\mathrm{Cd}$, cadmium; Cont, untreated control.

A

SREBP-1

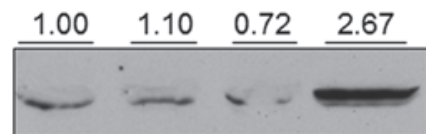

$\beta$-actin

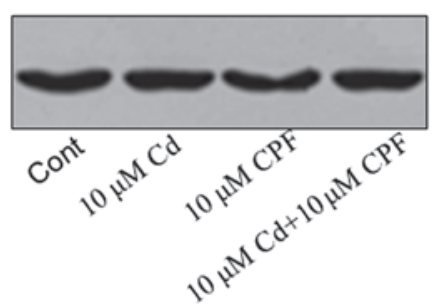

B

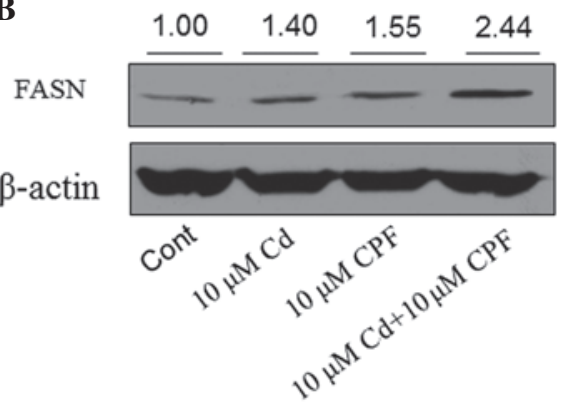

Figure 5. Western blot analysis of the proteins responsible for lipid metabolism in $\mathrm{HepG} 2$ cells treated with $\mathrm{CPF}$ and $\mathrm{Cd}^{2+}$. The cells were exposed to $10 \mu \mathrm{M}$ $\mathrm{CPF}$ and/or $\mathrm{Cd}^{2+}$ for $24 \mathrm{~h}$ and were subsequently collected and subjected to western blotting to determine the expression levels of (A) SREBP-1 and (B) FASN $\underline{\beta}$-actin was used as a loading control. CPF, chlorpyrifos; Cd, cadmium; SERBP, sterol regulatory element-binding protein; FASN, fatty acid synthase; Cont, untreated control. 
that the combined toxicity of $\mathrm{Cd}$ and $\mathrm{CPF}$ was attributable to the $\mathrm{Cd}-\mathrm{CPF}$ complex-facilitated intracellular transport (21). In the present study the combined toxicity of $\mathrm{CPF}$ and $\mathrm{Cd}$ was further confirmed using Alamar Blue and BrdU assays, and by selecting non-toxic concentrations (10 $\mu \mathrm{M}$ each) of CPF and Cd. As shown in Fig. 2A, cell viability was significantly reduced by $21 \%$ upon concomitant exposure of $\mathrm{Cd}^{2+}$ and $\mathrm{CPF}(\mathrm{P}<0.05)$ compared with the control or following individual treatment with either $\mathrm{Cd}^{2+}$ or $\mathrm{CPF}$, as demonstrated using an Alamar Blue assay. Similarly, in the BrdU incorporation assay, the concomitant exposure of $\mathrm{Cd}^{2+}$ and CPF markedly inhibited cell proliferation by $23 \%$, relative to the control or following individual treatment with $\mathrm{Cd}^{2+}$ or $\mathrm{CPF}$ $(\mathrm{P}<0.05$; Fig. 2B). In addition, a marked morphological change, of smaller and rounder cells, was observed in the cells simultaneously treated with $\mathrm{CPF}$ and Cd compared with the cells in the control and individual treatment groups (Fig. 3). Consistent with the cytotoxicity results, as discussed above, these morphological changes were indicative of cell death (Fig. 3). Taken together, these results revealed a significant synergistic cytotoxic effect of $\mathrm{Cd}^{2+}$ and $\mathrm{CPF}$ on the HepG2 cells, which was distinct from the effects of the individual chemicals.

To investigate the potential disturbance to lipid metabolism by the synergistic exposure of $\mathrm{CPF}$ and $\mathrm{Cd}$, the present study investigated the lipid concentrations in HepG2 cells post-treatment. To improve characterization of lipid metabolism, this was performed using a cell model treated with high glucose, as previously described (35). As shown in Fig. 4A, the concentration of triglycerides increased $\sim 2$-fold in cells exposed to simultaneous treatment of CPF and Cd compared with the untreated cells or single compound-treated cells. Similar to the changes in triglyceride levels, the concomitant exposure to $\mathrm{CPF}$ and $\mathrm{Cd}^{2+}(10 \mu \mathrm{M}$ each) significantly increased the total cholesterol concentration by $80 \%(\mathrm{P}<0.05)$ compared with the untreated cells or those treated with individual components $(\mathrm{P}<0.05$; Fig. 4B). These results collectively suggested that the synergistic effect of $\mathrm{CPF}$ and $\mathrm{Cd}$ markedly altered hepatic lipid metabolism, associated with cholesterol and triglyceride accumulation, in the hepatocytes.

The present study subsequently aimed to investigate the molecular mechanism underlying $\mathrm{CPF} / \mathrm{Cd}$-mediated disorders in lipid metabolism. SREBP is a critical regulator of hepatic lipid metabolism, including glucose transport, gluconeogenesis and lipolysis (43). The SREBP family consists of SREBP-1a, SREBP-1c and SREBP-2 (44), and these members are essential for regulating the expression of lipogenic enzymes, including acetyl-coenzyme A (CoA) carboxylase and FASN $(45,46)$. SREBP-1 is an important transcription factor, which stimulates lipogenic enzymes involved in liver fatty-acid synthesis, whereas SREBP-2 is relatively specific to the regulation of genes responsible for cholesterol synthesis and uptake, including low-density lipoprotein receptor and 3-hydroxy-3-methylglutaryl CoA reductase (44). The lipid accumulation, induced by exposure to $\mathrm{CPF} / \mathrm{Cd}$, may reside in the dysfunction of SREBP-1. The concentration of SREBP-1 was assessed in HepG2 cells following various treatments. Western blot analysis revealed that the expression of SREBP-1 was markedly increased by $>2$-fold in the cells following combined treatment with $\mathrm{CPF}$ and $\mathrm{Cd}$ compared with the untreated cells or those treated with CPF or Cd alone (Fig. 5A). The expression of
FASN was also markedly induced following treatment with $\mathrm{CPF} / \mathrm{Cd}$ ( $>2$-fold) compared with the untreated cells or those treated with the individual chemicals (Fig. 5B). These results demonstrated that the concomitant exposure of CPF and $\mathrm{Cd}$ induced hepatic fat accumulation through an increase in hepatic lipogenesis by increasing the expression levels of SREBP-1 and FASN.

Organophosphorus pesticides and heavy metals are amongst the most serious environmental pollutants. CPF, as a broad class of organophosphorus pesticides, is widely used throughout the world for agricultural and non-agricultural purposes $(1-4,13)$. Cd is a toxic metal, commonly found in industrial workplaces and diverse environmental substrates, which contaminates food chains, including crops and fruits (47). Cd is toxic to various cell types, even at low concentrations, and has a long biological half-life in humans (10-30 years) (13,21). However, CPF and Cd are often detected in identical environmental substrates and food chains, and they elicit similar damage to organisms, including hepatotoxicity $(16,17)$. Our previous study demonstrated the synergistic effect of CPF and $\mathrm{Cd}$ on reducing the viability of HepG2 cells (21). The present study demonstrated a novel HepG2 cell phenotype, caused by the $\mathrm{CPF} / \mathrm{Cd}$ complex, with significant cholesterol and triglyceride accumulation in the hepatocytes. The molecular mechanism underlying hepatic lipogenesis elicited by joint exposure of $\mathrm{CPF}+\mathrm{Cd}$ was found to occur through inducing the expression levels of SREBP-1 and FASN. Future investigations are required to determine the detailed mechanisms responsible for $\mathrm{CPF} / \mathrm{Cd}$-mediated action in lipogenesis.

\section{Acknowledgements}

This study was supported by grants from the Special Fund for Forest Scientific Research in the Public Welfare (no. 201304805), the National Natural Science Foundation of China (nos. 21377159 and 31201339), the Chinese Academy of Sciences (nos. KZCX2-EW-404 and XDB14000000) and the New Century Excellent Talents Program in University of the Ministry of Education (no. NCET-11-0587) . The authors would like to thank the laboratory members for their assistance with experiments and reagents.

\section{References}

1. Chung SW and Chan BT: Validation and use of a fast sample preparation method and liquid chromatography-tandem mass spectrometry in analysis of ultra-trace levels of 98 organophosphorus pesticide and carbamate residues in a total diet study involving diversified food types. J Chromatogr A 1217: 4815-4824, 2010.

2. Stepán R, Tichá J, Hajslová J, Kovalczuk T and Kocourek V: Baby food production chain: pesticide residues in fresh apples and products. Food Addit Contam 22: 1231-1242, 2005.

3. Szpyrka E, Kurdziel A, Slowik-Borowiec M, Grzegorzak M and Matyaszek A: Consumer exposure to pesticide residues in apples from the region of south-eastern Poland. Environ Monit Assess 185: 8873-8878, 2013.

4. Reiss R, Johnston J, Tucker K, DeSesso JM and Keen CL: Estimation of cancer risks and benefits associated with a potential increased consumption of fruits and vegetables. Food Chem Toxicol 50: 4421-4427, 2012.

5. Ivey MC and Palmer JS: Chlorpyrifos and 3,5,6-trichloro-2-pyridinol: residues in body tissues of swine treated with chlorpyrifos for hog louse and itch mite control. J Econ Entomol 72: 837-838, 1979. 
6. Fenske RA, Lu C, Barr D and Needham L: Children's exposure to chlorpyrifos and parathion in an agricultural community in central Washington State. Environ Health Perspect 110: 549-553, 2002.

7. Whyatt RM, Rauh V, Barr DB, et al: Prenatal insecticide exposures and birth weight and length among an urban minority cohort. Environ Health Perspect 112: 1125-1132, 2004.

8. Caughlan A, Newhouse K, Namgung U and Xia Z: Chlorpyrifos induces apoptosis in rat cortical neurons that is regulated by a balance between p38 and ERK/JNK MAP kinases. Toxicol Sci 78: 125-134, 2004.

9. Farag A, El Okazy AM and El-Aswed AF: Developmental toxicity study of chlorpyrifos in rats. Reprod Toxicol 17: 203-208, 2003.

10. Bagchi D, Bagchi M, Hassoun EA and Stohs SJ: In vitro and in vivo generation of reactive oxygen species, DNA damage and lactate dehydrogenase leakage by selected pesticides. Toxicology 104: 129-140, 1995.

11. Das PC, Cao Y, Rose RL, Cherrington N and Hodgson E: Enzyme induction and cytotoxicity in human hepatocytes by chlorpyrifos and N,N-diethyl-m-toluamide (DEET). Drug Metabol Drug Interact 23: 237-260, 2008.

12. Ki YW, Park JH, Lee JE, Shin IC and Koh HC: JNK and p38 MAPK regulate oxidative stress and the inflammatory response in chlorpyrifos-induced apoptosis. Toxicol Lett 218: 235-245, 2013.

13. Son YO, Lee JC, Hitron JA, Pan J, Zhang Z and Shi X: Cadmium induces intracellular $\mathrm{Ca}^{+}-$and $\mathrm{H}_{2} \mathrm{O}_{2}$-dependent apoptosis through JNK- and p53-mediated pathways in skin epidermal cell line. Toxicol Sci 113: 127-137, 2010.

14. Nzengue Y, Steiman R, Garrel C, Lefèbvre E and Guiraud P. Oxidative stress and DNA damage induced by cadmium in the human keratinocyte $\mathrm{HaCaT}$ cell line: role of glutathione in the resistance to cadmium. Toxicology 243: 193-206, 2008.

15. Zhou T, Zhou G, Song W, et al: Cadmium-induced apoptosis and changes in expression of p53, c-jun and MT-I genes in testes and ventral prostate of rats. Toxicology 142: 1-13, 1999.

16. Mansour SA,Belal MH,Abou-Arab AA and Gad MF: Monitoring of pesticides and heavy metals in cucumber fruits produced from different farming systems. Chemosphere 75: 601-609, 2009.

17. Fatta D, Canna-Michaelidou S, Michael C, et al: Organochlorine and organophosphoric insecticides, herbicides and heavy metals residue in industrial wastewaters in Cyprus. J Hazard Mater 145: 169-179, 2007.

18. Tuzmen N, Candan N, Kaya E and Demiryas N: Biochemical effects of chlorpyrifos and deltamethrin on altered antioxidative defense mechanisms and lipid peroxidation in rat liver. Cell Biochem Funct 26: 119-124, 2008.

19. Rai A, Maurya SK, Khare P, Srivastava A and Bandyopadhyay S: Characterization of developmental neurotoxicity of As, Cd, and $\mathrm{Pb}$ mixture: synergistic action of metal mixture in glial and neuronal functions. Toxicol Sci 118: 586-601, 2010.

20. Padilla S, Marshall RS, Hunter DL, et al: Neurochemical effects of chronic dietary and repeated high-level acute exposure to chlorpyrifos in rats. Toxicol Sci 88: 161-171, 2005.

21. Chen L, Qu G, Sun X, et al: Characterization of the interaction between cadmium and chlorpyrifos with integrative techniques in incurring synergistic hepatoxicity. PloS One 8: e59553, 2013.

22. Mingrone G, Rosa G, Greco AV, et al: Intramyocitic lipid accumulation and SREBP-1c expression are related to insulin resistance and cardiovascular risk in morbid obesity. Atherosclerosis 170 155-161, 2003.

23. Xia C, Li R, Zhang S, et al: Lipid accumulation product is a powerful index for recognizing insulin resistance in non-diabetic individuals. Eur J Clin Nutr 66: 1035-1038, 2012.

24. Krssak M and Roden M: The role of lipid accumulation in liver and muscle for insulin resistance and type 2 diabetes mellitus in humans. Rev Endocr Metab Disord 5: 127-134, 2004.

25. Moreau A, Téruel C, Beylot M, et al: A novel pregnane X receptor and S14-mediated lipogenic pathway in human hepatocyte. Hepatology 49: 2068-2079, 2009.

26. Hao J, Zhu L, Zhao S, Liu S, Liu Q and Duan H: PTEN ameliorates high glucose-induced lipid deposits through regulating SREBP-1/FASN/ACC pathway in renal proximal tubular cells. Exp Cell Res 317: 1629-1639, 2011.
27. Vazquez-Martin A, Colomer R, Brunet J, Lupu R and Menendez JA: Overexpression of fatty acid synthase gene activates HER1/HER2 tyrosine kinase receptors in human breast epithelial cells. Cell Prolif 41: 59-85, 2008.

28. Wu X, Qin L, Fako V and Zhang JT: Molecular mechanisms of fatty acid synthase (FASN)-mediated resistance to anti-cancer treatments. Adv Biol Regul 54: 214-221, 2014.

29. Jeon BN, Kim YS, Choi WI, et al: Kr-pok increases FASN expression by modulating the DNA binding of SREBP-1c and Sp1 at the proximal promoter. J Lipid Res 53: 755-766, 2012.

30. Choi WI, Jeon BN, Park H, et al: Proto-oncogene FBI-1 (Pokemon) and SREBP-1 synergistically activate transcription of fatty-acid synthase gene (FASN). J Biol Chem 283: 29341-29354, 2008.

31. Horton JD, Goldstein JL and Brown MS: SREBPs: activators of the complete program of cholesterol and fatty acid synthesis in the liver. J Clin Invest 109: 1125-1131, 2002.

32. Yahagi N, Shimano H, Hasty AH, et al: Absence of sterol regulatory element-binding protein-1 (SREBP-1) ameliorates fatty livers but not obesity or insulin resistance in Lep(ob)/Lep(ob) mice. J Biol Chem 277: 19353-19357, 2002.

33. Goda Y, Shimizu T, Kato Y, et al: Two acylated anthocyanins from purple sweet potato. Phytochemistry 44: 183-186, 1997.

34. Qu G, Liu S, Zhang S, et al: Graphene oxide induces toll-like receptor 4 (TLR4)-dependent necrosis in macrophages. ACS Nano 7: 5732-5745, 2013.

35. Hwang YP, Choi JH, Han EH, et al: Purple sweet potato anthocyanins attenuate hepatic lipid accumulation through activating adenosine monophosphate-activated protein kinase in human HepG2 cells and obese mice. Nutr Res 31: 896-906, 2011.

36. Akhtar N, Srivastava MK and Raizada RB: Assessment of chlorpyrifos toxicity on certain organs in rat, Rattus norvegicus. J Environ Biol 30: 1047-1053, 2009.

37. Zhukalin M,Blanksma MK, Silva TD, et al: Characterization and in vitro cytotoxicity testing of ethanolamine-derived cadmium chelating agents. Biometals 20: 61-72, 2007.

38. Gottschalg E, Moore NE, Ryan AK, et al: Phenotypic anchoring of arsenic and cadmium toxicity in three hepatic-related cell systems reveals compound- and cell-specific selective up-regulation of stress protein expression: implications for fingerprint profiling of cytotoxicity. Chem Biol Interact 161: 251-261, 2006.

39. Goel A, Dani V and Dhawan DK: Protective effects of zinc on lipid peroxidation, antioxidant enzymes and hepatic histoarchitecture in chlorpyrifos-induced toxicity. Chem Biol Interact 156: 131-140, 2005.

40. Dondero F, Piacentini L, Banni M, Rebelo M, Burlando B and Viarengo A: Quantitative PCR analysis of two molluscan metallothionein genes unveils differential expression and regulation. Gene 345: 259-270, 2005.

41. Ediz L, Hiz O, Ozkol H, Gulcu E, Toprak M and Ceylan MF: Relationship between anti-CCP antibodies and oxidant and anti-oxidant activity in patients with rheumatoid arthritis. Int J Med Sci 8: 139-147, 2011.

42. Steevens JA and Benson WH: Interactions of chlorpyrifos and methyl mercury: a mechanistic approach to assess chemical mixtures. Mar Environ Res 50: 113-117, 2000.

43. Viollet B, Foretz M, Guigas B, et al: Activation of AMP-activated protein kinase in the liver: a new strategy for the management of metabolic hepatic disorders. J Physiol 574: 41-53, 2006.

44. Yuan H, Shyy JY and Martins-Green M: Second-hand smoke stimulates lipid accumulation in the liver by modulating AMPK and SREBP-1. J Hepatol 51: 535-547, 2009.

45. Lee MS, Kim D, Jo K and Hwang JK: Nordihydroguaiaretic acid protects against high-fat diet-induced fatty liver by activating AMP-activated protein kinase in obese mice. Biochem Biophys Res Commun 401: 92-97, 2010.

46. Rawson RB: Control of lipid metabolism by regulated intramembrane proteolysis of sterol regulatory element binding proteins (SREBPs). Biochem Soc Symp 2003 221-231, 2003.

47. Leach RM, Jr., Wang KW and Baker DE: Cadmium and the food chain: the effect of dietary cadmium on tissue composition in chicks and laying hens. J Nutr 109: 437-443, 1979. 